\title{
Quantitative Single-Cell Differences in $\mu$-Opioid Receptor mRNA Distinguish Myelinated and Unmyelinated Nociceptors
}

\author{
Seth C. Silbert, Daniel W. Beacham, and Edwin W. McCleskey \\ Vollum Institute, Oregon Health and Science University, Portland, Oregon 97239
}

A remarkable feature of opioids is that they inhibit pain that persists from previous injuries without eliminating either the initial pain of a new injury or the protective reflexes triggered by it. Here we ask whether selective expression of the $\mu$-opioid receptor (MOR) gene in primary nociceptors (pain-sensing neurons) might contribute to this aspect of opioid specificity. We quantified single-cell levels of MOR mRNA and measured opioid inhibition of Ca channels on identified nociceptors and low-threshold mechanosensors (non-nociceptors) isolated from rats. Negligibly few non-nociceptors express MOR mRNA, thereby rendering nonpain sensations insensitive to opioids. Nearly half of nociceptors of all size classes also fail to express MOR mRNA or to respond to opioids. Among the opioid-responsive nociceptors, a gene dose-response relationship exists such that maximal opioid inhibition occurs when the MOR mRNA concentration of a cell is $>15$ pM. Almost all large, myelinated nociceptors express MOR mRNA below this level, whereas small, unmyelinated nociceptors are likely to express above it. Because myelinated nociceptors mediate anti-nociceptive reflexes, the data suggest that fine control of the MOR mRNA level contributes to a complex neural trait: the ability of opioids to suppress persistent pain without preventing response to a new injury.

Key words: opioid receptors; opiates; nociceptors; sensory neurons; pain; analgesia; calcium channels; single-cell PCR

\section{Introduction}

At analgesic doses, morphine binds only to the $\mu$-opioid receptor (MOR) (Goldstein and Naidu, 1989; Raynor et al., 1994), one of three cloned receptors activated by opioids (Li et al., 1996; Kieffer, 2000; Williams et al., 2001). The transgenic knock-out of MOR in mice completely eliminates morphine analgesia, and partial knock-down fractionally suppresses it (Matthes et al., 1996; Sora et al., 1997). Thus, the MOR is considered the receptor responsible for opiate analgesia.

Opioids distinguish different kinds of pain, powerfully suppressing second pain and having much less effect on first pain (Price et al., 1985; Cooper et al., 1986; Yeomans et al., 1996). Second pain develops slowly, over several seconds, and persists well after a noxious stimulus; first pain is the earliest sensation of injury, is transient, and is accompanied by reflexes that cause rapid withdrawal from the noxious stimulus (Lewis and Pochin, 1937; Torebjork and Hallin, 1973; Fields, 1987). Through specific targeting of second pain, opioids can relieve pain that persists from a previous injury without interrupting the pain or protective responses elicited by new injuries.

Action potentials for first pain are conducted from the periph-

Received March 28, 2002; revised Sept. 19, 2002; accepted Sept. 30, 2002.

The work was supported by grants from the National Institute on Drug Abuse (NIDA) and the National Institute of Neurological Disorders and Stroke (E.W.M.), by the Medical Scientist Training Program at Washington University (S.C.S.), and by a predoctoral training grant from NIDA (D.W.B.). We thank David Grandy for providing the MOR CDNA; John Scott and Susan Amara for sharing molecular biology equipment; Susan Brust for making the drawing in Figure 1; Sean Cook, MacDonald Christie, Christina Lessov, and John Williams for giving helpful comments on this manuscript; and Lori Vaskalis for providing help with all illustrations.

Correspondence should be addressed to Dr. Ed McCleskey, Vollum Institute, Oregon Health and Science University, L-474, Portland, OR 97239. E-mail: mccleske@ohsu.edu.

Copyright $\odot 2002$ Society for Neuroscience $\quad 0270-6474 / 02 / 220034-09 \$ 15.00 / 0$ ery to the spinal cord over rapidly conducting, myelinated axons, whereas signals for second pain travel over unmyelinated axons (C fibers) that conduct too slowly $(1 \mathrm{~m} / \mathrm{sec})$ to mediate rapid antinociceptive reflexes (Lewis and Pochin, 1937; Campbell and LaMotte, 1983). The synapse formed by nociceptive axons in the spinal cord is a major target of opioids (Arvidsson et al., 1995; Kohno et al., 1999). Spinal opioid selectivity arises because opioids target only synapses formed by nociceptors and opioids suppress synaptic activity caused by unmyelinated nociceptors more than that of myelinated nociceptors (Jurna and Heinz, 1979; Light and Willcockson, 1999). We sought a molecular explanation for this specificity by asking whether the selective expression of MOR mRNA explains differences in opioid sensitivity between nociceptors and non-nociceptors and nociceptors that differ in myelination.

We used the perforated patch-clamp technique to measure Ca-channel inhibition by a saturating dose of $\mathrm{D}-\mathrm{Ala}^{2}-\mathrm{N}-\mathrm{Me}-$ $\mathrm{Phe}^{4}$-Gly-ol ${ }^{5}$-enkephalin (DAMGO) (a MOR-selective agonist). The expression of MOR mRNA was quantitatively assayed in the same cells using competitive reverse transcription (RT)-PCR (Gilliland et al., 1990; Chehadeh et al., 1995), modified so it could be used on single cells. These methods were applied to dissociated sensory neurons that were identified either as nociceptors or as low-threshold (non-nociceptive) mechanosensors using the anatomical strategies illustrated in Figure 1. The relationship between myelination and opioid sensitivity was studied by comparing populations of nociceptors that differ in cell-body size, because most of the smallest sensory neurons have unmyelinated axons and most of the largest have myelinated axons (Harper and Lawson, 1985; Lee et al., 1986).

Our results indicate that non-nociceptive neurons and my- 


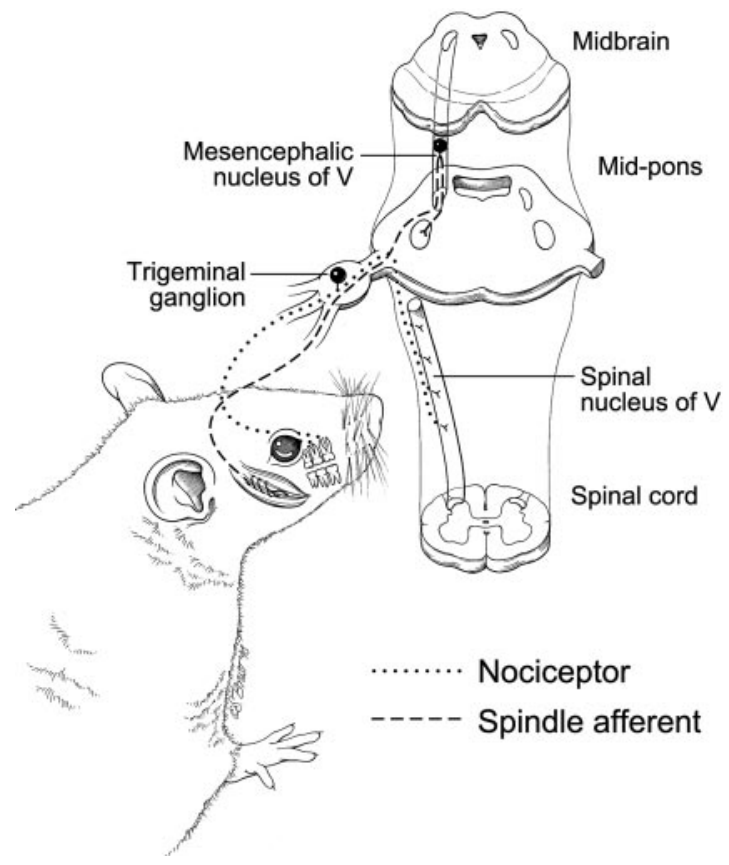

Figure 1. Strategy to distinguish nociceptors from mechanosensors. Low-threshold (nonnociceptive) mechanosensors were isolated from the mesencephalic nucleus of the fifth nerve, which contains only muscle spindle and fine-touch receptor afferents (Cody et al., 1972) (muscle spindle shown). Tooth pulp, an organ from which pain is the only conscious sensation (Ahlquist et al., 1984; Narhi et al., 1994), was used to obtain nociceptors. A dye (Dil), placed in small cavities drilled in rat molars $\sim 1$ week before harvesting the trigeminal ganglia, is transported to the cell body, where its fluorescence distinguishes tooth-pulp afferents from other dissociated trigeminal sensory neurons (Fig. 2).

elinated nociceptors use different molecular strategies to limit their opioid sensitivity: MOR mRNA is simply absent from the non-nociceptors, whereas it is quantitatively diminished in most large nociceptors compared with smaller ones. This suggests that fine control of the MOR transcript level, as opposed to simple on/off control of transcription, explains the high opioid sensitivity of unmyelinated nociceptors compared with myelinated ones. We also find that many nociceptors, including some small ones, express MOR mRNA at levels that give submaximal opioid responses; this suggests that increasing MOR mRNA production could increase opioid efficacy.

\section{Materials and Methods}

Cell preparation. Sensory neurons were used within $24 \mathrm{hr}$ of dissociation from adult Sprague Dawley rats and were stored at room temperature in L15 media plus nerve growth factor $(50 \mathrm{ng} / \mathrm{ml})$. Only cells with Cachannel current amplitudes of $>1 \mathrm{nA}$ were used for analysis. We observed no differences in Ca-channel current, opioid responses, or mRNA expression between freshly dissociated cells and those studied $1 \mathrm{~d}$ later. For example, in a random selection of tooth-pulp afferents studied immediately after dissociation versus those studied $24 \mathrm{hr}$ later, MOR mRNA was detectable in $51 \%$ of fresh $(n=33)$ and $57 \%$ of $24 \mathrm{hr}(n=120)$ cells; those that expressed MOR mRNA had mean concentrations of $13.8 \pm 3.2$ and $17.3 \pm 2.6 \mathrm{pm}$ in fresh and $24 \mathrm{hr}$ cells, respectively.

All methods for surgeries, dissections, dissociations, and cell storage are as described previously (Eckert et al., 1997), except for small adjustments of incubation times. The two surgeries used were shallow dental drilling to deposit crystals of DiI into the dentin and exposure of masseter muscle to inject with DiI dissolved in DMSO. The two dissections were of the trigeminal ganglion and the mesencephalic nucleus. Tissue dissociations used papain alone (mesencephalic nuclei) or papain, collagenase, and dispase (trigeminal ganglia). Any large, round neurons from the mesencephalic nucleus were used regardless of whether they were fluorescently labeled muscle spindle afferents.

Electrophysiology and cell harvest. In three ways, the procedures minimized RNA degradation that might occur during patch-clamp recording before PCR: (1) Solutions and surfaces were treated to eliminate RNase activity. (2) The perforated-patch method [using gramicidin, as described by Kyrozis and Reichling (1995)] was used because it minimally disrupts the intracellular environment. (3) Recording times were minimized by using voltage ramps to measure peak Ca-channel currents rapidly and to detect whether series resistance artifacts distort the currentvoltage curve. All required voltage protocols and recordings were completed within $\sim 5 \mathrm{~min}$, after which cells were promptly harvested.

Voltage ramps ( $420 \mathrm{msec}$ from $-80 \mathrm{mV}$ to $+20 \mathrm{mV}$ ) were delivered at $20 \mathrm{sec}$ intervals, and opioid action was measured $20 \mathrm{sec}$ after the application of $1 \mu \mathrm{M}$ DAMGO, a time sufficient to complete opioid inhibition (Wilding et al., 1995) and a concentration sufficient for a maximal response (Seward et al., 1991). Preliminary experiments confirmed that stimulating with voltage ramps or with voltage pulses gave the same fractional Ca-channel inhibition. Nifedipine was included in a bath solution to block opioid-insensitive L-type Ca channels (Rusin and Moises, 1995) at a concentration $(10 \mu \mathrm{M})$ reported not to affect other Ca channels (Triggle, 1999). Because L-channel expression varied from 20 to $50 \%$ of the total $\mathrm{Ca}^{2+}$ current in different cells, we blocked L channels so that their variable expression did not cause artifactual variation in opioid efficacy. Series resistance compensation, initially set at $\sim 50 \%$, was increased if the Ca-channel current-voltage curve had a negative slope region that was artifactually sharp. Currents through Ca channels were blocked by $1 \mathrm{~mm} \mathrm{Cd}^{2+}$ at the end of each run; the resulting record was subtracted from others to isolate $\mathrm{Ca}$-channel currents. Calculation of the percentage of inhibition included correction for a constant fractional rundown rate using the following algorithm: $X=100\left(1-a c / b^{2}\right)$, where $X$ is the percentage of inhibition, $a$ and $b$ are current amplitudes $20 \mathrm{sec}$ apart before drug application, and $c$ is the amplitude $20 \mathrm{sec}$ after drug application.

All solutions were prepared using nuclease-free reagents and diethylpyrocarbonate-treated, deionized, distilled water, and stored in RNasefree plastics or baked $\left(200^{\circ} \mathrm{C}\right.$ overnight $)$ glass. The perforated-patch recording pipette contained $35 \mu \mathrm{g} / \mathrm{ml}$ gramicidin in a solution of (in $\mathrm{mm}): 150 \mathrm{CsCl}, 1 \mathrm{EGTA}$, and 10 HEPES, pH 7.3-7.4, adjusted with $\mathrm{CsOH}, 300-310 \mathrm{mOsm}$. In cases in which cells were not harvested for PCR, standard whole-cell recording was used, and the pipette contained (in mM): $100 \mathrm{Cs}$-methanesulfonate, $20 \mathrm{CsCl}, 10 \mathrm{Na}_{2}$ phosphocreatine, 4 $\mathrm{Na}_{2} \mathrm{ATP}, 0.5 \mathrm{Na}_{3} \mathrm{GTP}, 5 \mathrm{Cs}_{5}$ [1,2-bis(2-aminophenoxy)ethane- $N, N, N^{\prime}, N^{\prime}$ tetraacetic acid], and 10 HEPES, pH 7.3-7.4, adjusted with $\mathrm{CsOH}$, 300-310 mOsm. When recording Ca-channel activity, the extracellular solution contained (in mM): $1 \mathrm{BaCl}_{2}, 140$ tetraethylammonium-Cl, 10 HEPES, and 0.01 nifedipine, $\mathrm{pH}$ 7.3-7.4. At all other times, cells were exposed to physiological saline (in $\mathrm{mm}$ ): $135 \mathrm{NaCl}, 5 \mathrm{KCl}, 2 \mathrm{CaCl}_{2}, 1$ $\mathrm{MgCl}_{2}, 10$ glucose, and 10 HEPES, $\mathrm{pH}$ 7.3-7.4, 300-310 mOsm.

The entire cell was harvested for RT-PCR so that all mRNA was counted. Recording pipettes gave inconsistent harvests, so a second, larger pipette was used. These were fire-polished to an inner diameter of $6-8 \mu \mathrm{m}$ (for cells of $<40 \mu \mathrm{m}$ diameter) or 8-12 $\mu \mathrm{m}$ (for larger cells), and filled with $<1 \mu$ l of harvest solution (in mM: $135 \mathrm{KCl}, 1$ EGTA, and 5 Tris, $\mathrm{pH}$ 8.2). The contents of the pipette were expelled into the bottom of a thin-walled $200 \mu \mathrm{l}$ PCR tube (PerkinElmer Life Sciences, Boston, MA), containing $10 \mu \mathrm{l}$ of frozen primer annealing buffer (see below). The tubes were kept frozen in an ethanol/dry ice bath, and RT was performed at the end of the day. Sham harvests were performed by dipping a pipette into the culture dish, manipulating the tip to within a few micrometers of the culture surface, applying gentle suction, and carrying the contents through RT-PCR. Shams were assembled each day of recording; in >100 sessions, no MOR mRNA contamination was found, and glyceraldehyde-3-phosphate dehydrogenase (GPD) mRNA (50 molecules) was found only once.

Quantitative PCR. We used a variation of competitive PCR (Gilliland et al., 1990) rather than real-time PCR, because real-time PCR is reported to be less able to detect small numbers of DNA molecules (Tkatch et al., 2000). The essential PCR controls are: (1) measurement on each cell for 
a constitutively expressed "housekeeping" gene (GPD, a metabolic enzyme); (2) addition into each PCR tube of a known amount of competitor sequence that is amplified by the same PCR primers as the wild-type (w.t.) DNA; (3) a calibration ladder made for each PCR run by performing the reaction on known amounts of the competitor and wild-type DNAs; and (4) addition of a known amount of a mutant GPD RNA to quantify the RT reaction for each cell (see below). We analyzed the ratios of the densities of wild-type and competitor PCR products. We picked up the entire cell, rather than harvesting a variable amount of cytoplasm, so that total mRNA levels were measured (Sucher and Deitcher, 1995). The method does not assume that wild-type and mutant DNA sequences are amplified identically in the PCR. Rather, it assumes only that whatever wild-type-to-mutant amplification efficiency occurred in the calibration tubes used in any particular PCR run also occurred in the cell tubes for that run.

$\mathrm{RT}$ reactions had, in a $20 \mu \mathrm{l}$ volume, $1 \times$ Superscript II buffer (Invitrogen, Carlsbad, CA), $5 \mu \mathrm{m}$ random hexamers (Roche Applied Science, Indianapolis, IN), $0.5 \mathrm{U} / \mu \mathrm{l}$ RNasin (Amersham Biosciences, Arlington Heights, IL, or Invitrogen), $0.5 \mathrm{~mm}$ of each deoxyNTP (dNTP) (Roche Applied Science), $5 \mathrm{U} / \mu \mathrm{l}$ Superscript II reverse transcriptase (Invitrogen), and $10^{4}$ molecules of a mutant GPD mRNA. The reaction was assembled and performed in two stages: one for cell disruption and primer annealing at low ionic strength and one for RT. RT reaction was $60 \mathrm{~min}$ at $42^{\circ} \mathrm{C}$, followed by $15 \mathrm{~min}$ at $75^{\circ} \mathrm{C}$; products were then stored at $-20^{\circ} \mathrm{C}$. Sham RTs lacking the mutant mRNA and cell harvests were assembled with each reaction set and were subsequently used to assemble calibration tubes for the PCR sets.

Two rounds of PCR using nested primers generated visible ethidiumstained products. The first round was a multiplex reaction using PCR primers for both MOR and GPD sequences; $50 \mu$ l PCRs were assembled using one-half of the contents $(10 \mu \mathrm{l})$ of each RT reaction. Mutant competitor DNA of MOR ( 12 copies) or GPD (500 copies) was added to the first-round reaction by the serial dilution of DNA stocks quantified spectrophotometrically; $1 \mu \mathrm{l}$ aliquots of the first-round reaction product were the starting material for the second-round PCRs, which used primers for either MOR or GPD that were complementary to sequences internal to those used for the first round. All reaction tubes in the set contained $50 \mu \mathrm{l}$. The first, multiplexed PCR round had 25 cycles; the second round for MOR had 24 cycles; the second round for GPD had 17 cycles. Denaturation, annealing, and extension steps were $98^{\circ} \mathrm{C}$ for $5 \mathrm{sec}$, $54.4^{\circ} \mathrm{C}$ for $30 \mathrm{sec}$, and $70^{\circ} \mathrm{C}$ for $2 \mathrm{~min}$, except for the first five cycles, during which the extension time was lengthened to $5 \mathrm{~min}$. For the first round, primer concentrations were $200 \mathrm{nM}$, nucleotides were $150 \mu \mathrm{M}$ (substituting dUTP for dTTP). For the second round, the primers were $500 \mathrm{nM}$ and the nucleotides were $250 \mu \mathrm{M}$. Other reaction components were: $50 \mathrm{~mm}$ Tris- $\mathrm{HCl}, \mathrm{pH} 8.7$ at $23^{\circ} \mathrm{C} ; 16 \mathrm{~mm}\left(\mathrm{NH}_{4}\right)_{2} \mathrm{SO}_{4} ; 150 \mu \mathrm{g} / \mathrm{ml}$ BSA; $10-15 \mathrm{~mm} \mathrm{KCl} ; 3-5 \mathrm{~mm} \mathrm{MgCl} ; 100 \mu \mathrm{M}$ tetramethylammonium chloride; 6-8\% DMSO; and $4 \mathrm{mU} / \mu \mathrm{l}$ KlenTaq I (Barnes, 1992).

Primers, selected using Oligo version 5.0 (National Biosciences, Plymouth, MA) and purchased from Oligos Etc (Wilsonville, OR), spanned the splice site between exons 2 and 3 for MOR and those between exons 5 and 8 for GPD. The following primers were used: MOR outer primers, 5'-GCGACTGCTCAGACCCCTTAGCTC-3' and $5^{\prime}$-TCTGGAATCGTGATCAGCGCTTTG-3', corresponding to MOR 215-238(+) and 1112-1089(-), respectively; MOR inner primers, $5^{\prime}$-GGAACATGGCCCTTCGGAACCATC- $3^{\prime}$ and $5^{\prime}$-TACCAGGTTGGGTGGGAGAACGTG-3', corresponding to MOR 574-597(+) and 863-840(-), respectively; GPD outer primers, 5'-TGGTGCTGAGTATGTCGTGGAGTC-3' and 5'-AGAATGGGAGTTGCTGTTGAAGTC-3', corresponding to GPD 335-358(+) and 941-918(-), respectively; GPD inner primers, 5' -GGGTGTGAACCACGAGAAATATGA-3' and 5' AGCACCAGTGGATGCAGGGATGAT-3', corresponding to GPD $464-487(+)$ and 704-681(-), respectively.

PCR products were electrophoresed through a $1.0-1.3 \%$ agarose gel and stained with ethidium bromide. All single-cell PCR analyses used ratios of the band intensities of wild-type and mutant DNA.

Quantifying RT. To convert the number of DNA molecules counted in the PCR into the number of mRNA molecules that were in the cell, we quantified the RT reaction for a housekeeping gene in each cell and

\section{A Nociceptors}
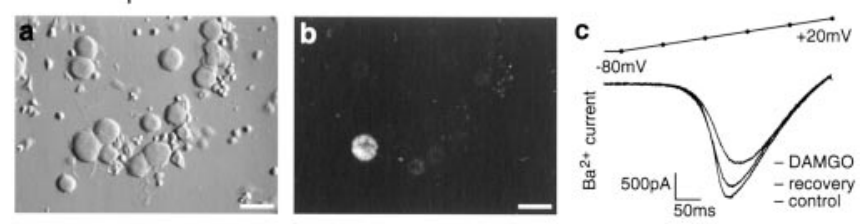

B Mechanosensors
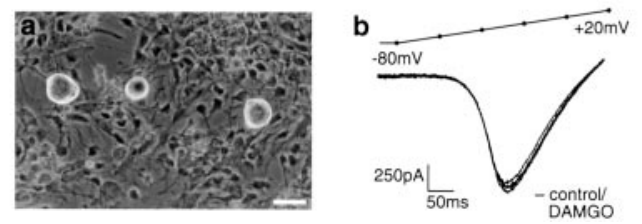

Figure 2. Opioids inhibit Ca channels on nociceptive but not on non-nociceptive sensory neurons. $A$, Bright-field $(a)$ and fluorescence $(b)$ photographs of sensory neurons dissociated from the trigeminal ganglion 1 week after Dil was placed in tooth pulp; the fluorescent cell would be taken as a tooth-pulp nociceptor. $A, c$, Nociceptor currents carried by $1 \mathrm{~mm} \mathrm{Ba}{ }^{2+}$ through Ca channels activated by the indicated ramp of voltage just before (control), 20 sec after the application of $1 \mu \mathrm{M} \mathrm{DAMGO}$, and 40 sec after removal (recovery). A control record in $1 \mathrm{~mm}$ $\mathrm{Cd}^{2+}$ (which blocks all Ca channels) was subtracted from all test records. Opioid receptor antagonists (10 $\mu$ m naloxone or $200 \mathrm{~nm}$ (TAP) fully blocked DAMG0 action (data not shown). $B$, $a$, Bright-field photograph of three neurons dissociated from the mesencephalic nucleus and placed on a bed of glial cells; all three would be accepted as low-threshold (non-nociceptive) mechanosensors. $B, b$, Ca channels were not inhibited by DAMGO in this or any other mesencephalic neuron. Scale bars, $30 \mu \mathrm{m}$.

assumed that this same RT efficiency applied to the MOR gene. RT efficiency is the number of cDNA molecules made in the RT reaction per mRNA molecule present in the reaction. Referring to Figure $3 A$, the second GPD mRNA mutant, $\mathrm{m} 2$, enables the measurement of GPD mRNA for each cell. w.t./m1 and w.t./m2 ratio calibrations are plotted separately to measure the cDNA and mRNA, respectively. The ratio of GPD cDNA/mRNA is taken as the RT efficiency for a given cell. Dividing MOR cDNA by the RT efficiency gives the number of MOR mRNA molecules. RT efficiency, which averaged 0.175 , varied from $\sim 0.2$ to 0.1 in different cells. Data from cells $A$, $J$, and $K$ in Figure 3, $A$ and $B$, illustrate effects of this variation. For example, cells $A$ and $J$ had the same number of MOR cDNA molecules (22), but, because their RT efficiency differed, we conclude that cell $A$ had 175 mRNA MOR mRNA molecules and cell $J$ had 215.

Statistics. Statistics calculations used Prism (GraphPad Software Inc., San Diego, CA). Error bars on averaged data indicate SEM; error bars on fractional data indicate the $68 \%$ confidence interval. Averaged data were compared using one-way ANOVA followed by Tukey's multiple comparison test or a post-test for linear trend. Ranked data were analyzed for correlation using the nonparametric Spearman test. Confidence intervals and statistical significance of fractional data are from the $\chi^{2}$ test of contingency tables.

\section{Results}

Opioids spare Ca channels on non-nociceptive neurons and on some nociceptors

Depolarizing ramps of voltage evoked $\mathrm{Ba}^{2+}$ current through voltage-gated $\mathrm{Ca}$ channels in fluorescently identified toothpulp afferents (nociceptors) (Fig. 2A) or mesencephalic nucleus sensory neurons (low-threshold mechanosensors) (Fig. 2B). DAMGO $(1 \mu \mathrm{M}$, a saturating concentration for the MOR) reversibly inhibited peak $\mathrm{Ba}^{2+}$ current in most nociceptors (Fig. 2Ac) but not in any mechanosensors (Fig. 2Bb, Table 1). Evidently, opioids spare nonpainful sensations because they fail to inhibit Ca channels and neurotransmitter release from non-nociceptive sensory neurons.

DAMGO inhibition of nociceptors varied widely (range, $0-49 \%$ ), with approximately one-third of them being clearly in- 
Table 1. MOR sensitivity and MOR mRNA in nociceptive and non-nociceptive sensory neurons

\begin{tabular}{lll}
\hline & Ca channel inhibition $>10 \%$ & Detectable MOR mRNA \\
\hline Nociceptors & $77 / 182$ & $109 / 191$ \\
Mechanosensors & $0 / 20$ & $2 / 72$
\end{tabular}

Denominators indicate the total number of neurons tested. Numerators give the number that exhibited at least $10 \%$ inhibition by $1 \mu \mathrm{m}$ DAMGO (left column) or had a detectable product of the RT-PCR for MOR mRNA (right). Many but not all nociceptors are opioid sensitive and have MOR mRNA. Mechanosensors are opioid insensitive and, with rare exceptions, did not have detectable MOR mRNA.

sensitive, as shown previously in tooth-pulp afferents (Taddese et al., 1995) and in nociceptors identified by long durations of action potential (Abdulla and Smith, 1998). To independently confirm that some nociceptors are insensitive to opioids, we used capsaicin, which activates a particular subset of nociceptors that senses noxious heat (Kirschstein et al., 1999; Nagy and Rang, 1999). A third of the capsaicin-sensitive sensory neurons had little or no response to DAMGO. Thus, regardless of whether nociceptors are identified by the innervation of tooth pulp, duration of action potential, or capsaicin sensitivity, a significant fraction fail to respond to opioids, and inhibition is submaximal in many others.

\section{Nociceptors selectively transcribe the MOR gene}

The MOR inhibits primarily N-type Ca channels in sensory neurons (Rusin and Moises, 1995); it does so through a simple signaling path involving direct mediation by a G-protein (Moises et al., 1994; Wilding et al., 1995). The difference in opioid sensitivity of nociceptors and mechanosensors is not attributable to differences in $\mathrm{N}$-channel expression, because $\omega$-conotoxin GVIA, an $\mathrm{N}$-channel-selective toxin, inhibited $\mathrm{Ba}^{2+}$ currents to the same degree on mechanosensors and nociceptors ( $44 \pm 4 \%, n=6$, and $41 \pm 3 \%, n=12$, respectively).

\section{Single-cell PCR}

We then asked whether opioid selectivity arises from selective transcription of the MOR gene. We picked up individual neurons and performed quantitative RT-PCR to detect and count the MOR mRNA in each cell. Figure 3 illustrates our method, which is a variation of competitive PCR (Gilliland et al., 1990), along with a method to quantify the RT reaction so that the mRNA is counted. Competitive PCR was used instead of real-time PCR, because real-time PCR is reported to be weak at detecting low numbers of cDNA molecules (Tkatch et al., 2000). In addition to quantifying mRNA, our method tests for three kinds of false negatives: failure of the PCR, failure of the RT, and failure of the cell harvest.

Figure 3 is like most of our reactions in that two MOR cDNA molecules were detectable. This corresponds to a resolution of four MOR cDNA molecules per cell (because one-half of the RT reaction was used for the MOR PCR) and 23 MOR mRNA molecules per cell (assuming our mean RT efficiency of $5.7 \mathrm{mRNA}$ / cDNA). Dividing by the volume of a $30-\mu \mathrm{m}$-diameter cell gives a cellular detection threshold of $2 \mathrm{pM}$ MOR mRNA. Cells with robust expression had $\sim 100$ copies of MOR mRNA, 1000 copies of neurokinin peptide mRNA (data not shown), and 10,000 copies of mRNA for the metabolic enzyme GPD.

The final lane, $S h$, from a sham harvest, has no evident w.t. MOR and no w.t. GPD; however, it has a mut band, which confirms that PCR for MOR worked, and an $\mathrm{m} 2$ band, which confirms that the RT worked. In contrast, cell I, which also has no detectable w.t. MOR, has w.t. GPD, mut, and $\mathrm{m} 2$; this shows that the cell harvest, PCR, and RT were all successful,
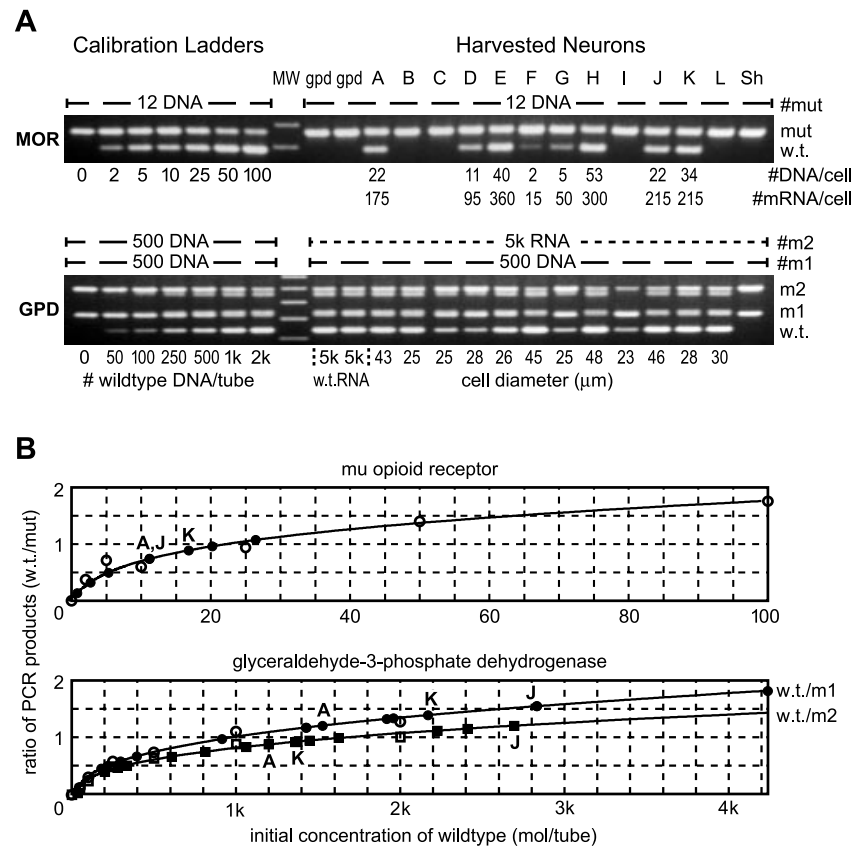

Figure 3. Use of competitive RT-PCR to quantify single-cell MOR and GPD mRNAs. $A$, Ethidium-stained agarose gels of PCR products for MOR (top) and GPD (bottom) for 12 individual nociceptors (lanes $A-L$ ) and seven calibration tubes (left lanes). Each gel shows the reaction products from a particular run of the PCR machine. mut and $m 1$, Mutants of MOR and GPD DNA, respectively, having 78 and $88 \mathrm{bp}$ insertions between primer sites. Twelve molecules of mut and 500 molecules of $m 1$ were seeded into their PCR tubes. RT reactions were seeded with the indicated amount of synthetic RNA for m2, which has a 268 bp insertion into the GPD sequence. Calibration tubes, assembled and processed along with the cell tubes, contain the indicated number of w.t. MOR or GPD DNA and either 12 (MOR) or 500 (GPD) mutant molecules. MW, Molecular weight. $B$, Positive MOR bands were quantified (numbers below MOR gel in $A$ ) by comparison with calibration ladders and correcting for RT efficiency to obtain mRNA values. Ratios of w.t./mutant band intensities in each calibration tube are plotted against the number of initial w.t. molecules (open symbols). Polynomial equations (curves) fitted to these data are used to interpolate initial cellular w.t. content from the w.t./mutant product ratios from each cell (solid symbols).

indicating that the MOR mRNA in cell I was truly below the detection threshold. Approximately $10 \%$ of apparent MORnegative cells failed to exhibit w.t. GPD bands, indicating that the cell harvest failed and requiring discarding of the data; we never had failures of RT and PCR.

\section{Nociceptors versus non-nociceptors}

We successfully measured MOR mRNA levels in 191 tooth-pulp afferents (Figs. 3, 4A) and 72 mesencephalic mechanosensory neurons (Fig. $4 B$, Table 1). A majority (60\%) of the tooth-pulp nociceptors contained detectable MOR mRNA, but only two mechanosensors tested positive. The number of MOR mRNA molecules varied extensively in different nociceptors: the mean (considering only those with detectable MOR mRNA) was 227 molecules and the median was $160 ; 50 \%$ of the positives were between 60 and 290 molecules. These small levels are in contrast to the mean of 13,100 molecules of GPD mRNA in the same cells.

One of the two positive mechanosensors is in Figure $4 B$ (lane $I)$. We asked whether these two cells are rare expressers or whether all cells have MOR mRNA at low levels that are usually below our limit of resolution. Using pooled samples, we concluded that only rare cells from the mesencephalic nucleus have MOR mRNA (Fig. 4B, legend). The absence of MOR mRNA in the overwhelming fraction of non-nociceptive sensory neu- 
A

Nociceptors

Calibration Ladders gpd gpd A B C D E F G H I J $\mathrm{K}$ L $M$
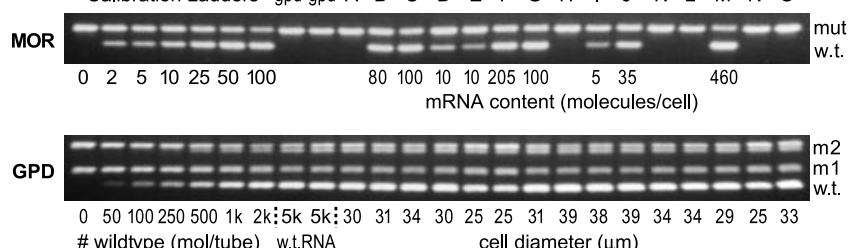

B

Mechanosensors
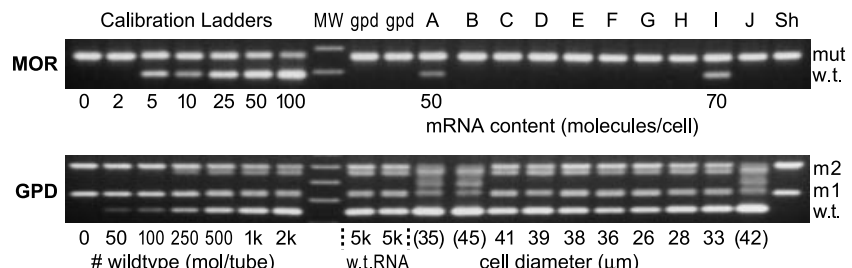

Figure 4. Most nociceptors, but only rare mechanosensors, transcribe MOR mRNA. A, MOR and GPD mRNA amplified and quantified from 15 single tooth-pulp afferents (Ianes $A-0$ ). MOR mRNA expression spans from below the detection threshold to 460 molecules per cell (60 pm, assuming equal distribution throughout the spherical cell); $60 \%$ of 191 nociceptors tested had detectable MOR mRNA (Table 1). B, MOR and GPD mRNA amplified and quantified from seven individual mesencephalic neurons (Ianes $(-I)$ and three pooled samples of either five (lanes $A$ and $B$ ) or 10 (lane J) mesencephalic neurons. (ell I is one of only two (of 72) individual mesencephalic neurons that had detectable MOR mRNA. We used the pooled samples to determine whether most mesencephalic neurons express at nonzero levels below our detection threshold or whether rare ones express high levels of MOR mRNA. Six pooled samples were prepared (4 with 5 cells in each and 2 with 10). MOR mRNA was present in only three of these pools, at levels $(50,100$, and 250 molecules) similar to those in single nociceptors and similar to the two individual positive cells (lane $A$ is a positive pool; lanes $B$ and $J$ are negative pools). This argues that rare cells in the mesencephalic preparation have substantial MOR mRNA, because all pools should be positive if the majority of cells express at levels just below our detection threshold. $M W$, Molecular weight; GPD, glycerol-3-phosphate dehydrogenase.

rons indicates that only nociceptors effectively transcribe the MOR gene.

\section{Large nociceptors have low MOR response and low MOR mRNA}

Might selective transcription also explain why opioids fail to suppress antinociceptive reflexes? This could occur through selective suppression of MOR mRNA in myelinated nociceptors, the cells that trigger these reflexes. Tooth pulp is well suited for addressing this question because it is rich in myelinated afferents, and the only sensation these evoke is pain (Ahlquist et al., 1984; Narhi et al., 1994). Moreover, the tooth has clear psychophysical correlates to first (sharp, shooting) and second (dull) pain, mediated, as in the skin, by myelinated and unmyelinated axons, respectively (Jyvasjarvi and Kniffki, 1987). Myelination was studied by comparing populations of tooth-pulp afferents that differ in cellbody diameter; the larger the cell, the more likely it has a myelinated axon (Harper and Lawson, 1985; Lee et al., 1986). We asked whether the lower mean opioid sensitivity of large nociceptors that we reported previously (Taddese et al., 1995) correlates with low MOR mRNA expression (Fig. 5).

\section{Electrophysiology}

Ca-channel inhibition by DAMGO was measured in 182 toothpulp nociceptors. Ranking them by size confirmed that opioid sensitivity decreases as the cell-body diameter increases (Spearman rank-order correlation coefficient, $r_{\mathrm{s}}=0.19 ; p=0.011$ that this could occur by chance). The reason is evident from binning
A $\mathrm{Ca}^{2+}$ channel inhibition

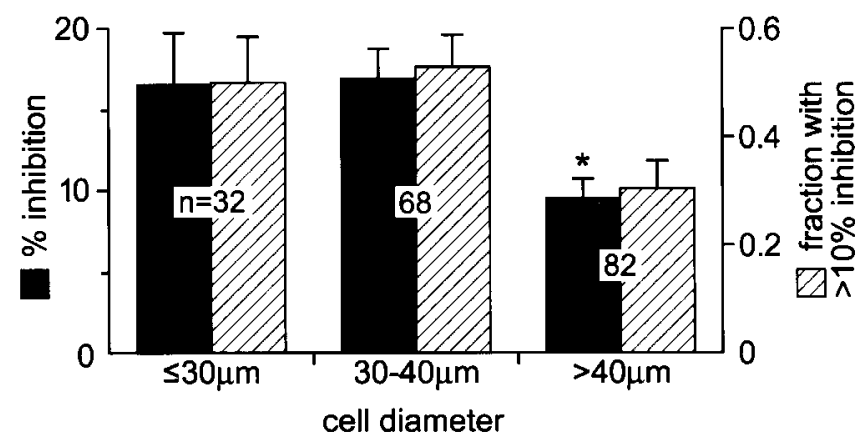

B mRNA expression

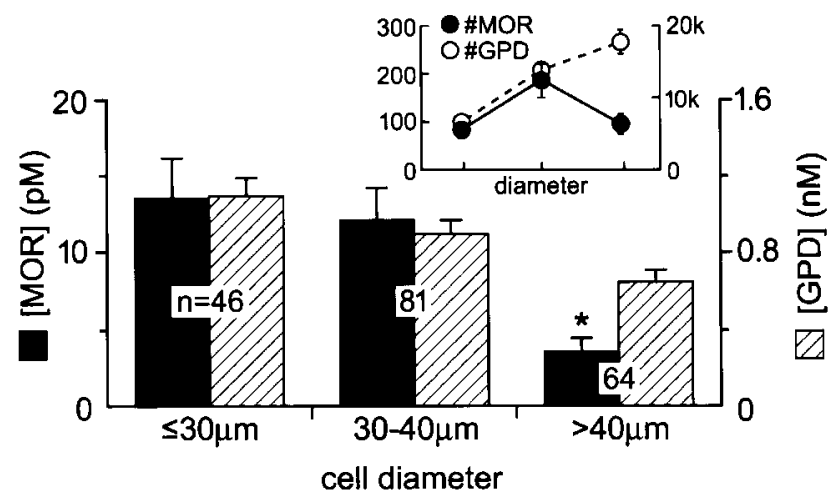

Figure 5. Large nociceptors have a low opioid response and have low MOR mRNA levels. $A$, Mean \pm SEM percentage of Ca-channel inhibition by $1 \mu \mathrm{m} \mathrm{DAMGO} \mathrm{(black} \mathrm{columns,} \mathrm{left} \mathrm{axis)} \mathrm{and}$ the fraction ( $\pm 68 \%$ confidence interval) of cells inhibited by $>10 \%$ (hatched columns, right axis) in tooth-pulp afferents of different cell-body diameters. The medians were 12,17 , and $5.5 \%$ for the small $(<30 \mu \mathrm{m})$, medium $(30-40 \mu \mathrm{m})$, and large $(>40 \mu \mathrm{m})$ cells, respectively. There were nonresponders and very large responders ( $>40 \%$ inhibition) in each bin. $B$, Inset, The mean number of GPD (open circles, right axis) and MOR ( filled circles, left axis) mRNA molecules for small, medium, and large nociceptors. GPD mRNA systematically increases with cell size, as expected when an increasing amount of cytoplasm is harvested. In contrast, MOR mRNA drops in the largest cells after increasing with cell size between the smaller cells. B, Mean concentration (moles per volume, assuming a spherical cell) of MOR mRNA (black columns, left axis) is lowest in the largest nociceptors. Asterisks indicate a significant difference from the other two means $(p<0.05)$.

the data (Fig. $5 A$ ): the mean DAMGO inhibition of Ca channels is less in the largest cells (diameters of $\geq 40 \mu \mathrm{m}$ ), the population most enriched in myelinated axons. The results qualitatively agree with previous reports (Taddese et al., 1995; Borgland et al., 2001), which suggested that unmyelinated nociceptors have greater opioid responses than the myelinated ones. Our previous report demonstrated larger opioid differences between small and large neurons than we show here. This is explained by the nature of data acquisition. Previously, we chose the largest and smallest labeled cells possible in a culture dish, because this is the most certain way to compare myelinated and unmyelinated cells (Harper and Lawson, 1985). Here, we investigated all labeled cells, a method that allows use of the Spearman rank analysis and, thus, an independent test of the previous conclusion.

MOR and GPD mRNA expression

MOR and GPD mRNA levels were measured in 191 tooth-pulp nociceptors that ranged from 20 to $50 \mu \mathrm{m}$ in diameter. The number of GPD mRNA molecules increased almost perfectly as the cell diameter increased (Spearman $r_{\mathrm{s}}=0.49 ; p<0.0001$ ). Figure $5 B$, inset, shows the mean number of GPD mRNA molecules 

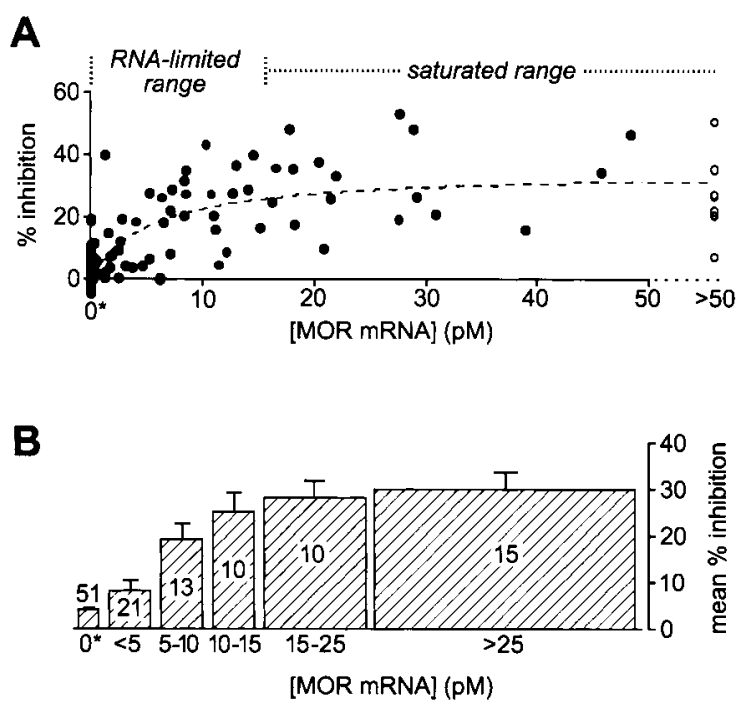

Figure 6. Opioid sensitivity is limited when the MOR mRNA is $<15 \mathrm{pm}$. A, Percentage of inhibition of Ca channels by DAMGO versus the cellular MOR mRNA concentration for 120 toothpulp afferents (each point from a single cell). The origin $\left(0^{*}\right)$, which has 51 points, denotes cells with no detectable MOR mRNA. The dashed curve is the best fit $\left(R^{2}=0.51\right)$ of a single site isotherm $\left(K_{1 / 2}=5.4 \mathrm{pm} ; B_{\max }=35 \%\right)$. $B$, The same data expressed as means \pm SEM for bins of MOR mRNA concentrations. The mean opioid response systematically rises with MOR mRNA concentration until it saturates at $\geq 15 \mathrm{pm}$. The number of cells in each bin is indicated. Except for the $10-15$ pм versus $>25$ pм bins, values for non-neighboring bins differed significantly $(p<0.05)$.

(open circles, right axis) in the three different bins of cell-body diameter. The systematic increase in GPD mRNA levels is consistent with the increasing metabolic demands of larger cells and confirms GPD as a useful housekeeping gene.

In clear contrast to GPD, the number of MOR mRNA molecules fails to correlate statistically with nociceptor cell diameter (Spearman $r_{\mathrm{s}}=-0.085 ; p=0.24$ ). The reason is evident when data are binned by diameter. Like GPD, the mean number of MOR mRNA molecules (Fig. 5B, inset, solid circles, left axis) increases with cell size between the small- and medium-cell-size bins. However, the mean in the largest cells drops dramatically from the expected trend. Normalizing expression to cell-body size, dividing either by cell volume (Fig. $5 B$ ) or by surface area (data not shown), emphasizes the similar trends for MOR mRNA expression and opioid response: both drop in the largest population of tooth-pulp afferents.

\section{Relationship between MOR mRNA concentration and Ca- channel inhibition in single nociceptors \\ Gene dose-response relationship}

Hoping to gain insight into the mechanism for the apparent relationships between nociceptor size, opioid response, and MOR mRNA, we obtained a single-cell MOR mRNA dose-response relationship. Each point in Figure $6 A$ expresses, for a particular labeled tooth-pulp afferent, the percentage of inhibition by DAMGO ( $y$-axis) and the concentration of MOR mRNA ( $x$ axis). We used concentration (moles of MOR mRNA per cell spherical volume), because it controls for the 15-fold span of cell volumes between the different-sized cells (see Discussion).

As expected of single-cell data, there is considerable scatter, yet several clear conclusions arise. Of the 120 cells successfully studied, 51 had no MOR mRNA above our detection threshold (points at the origin); only four of the 51 had opioid inhibition of
$>10 \%$. In contrast, most cells that had detectable MOR mRNA had obvious responses to DAMGO. Thus, the fraction of nociceptors reported to be opioid-insensitive (Taddese et al., 1995; Abdulla and Smith, 1998) exhibits little or no expression of the MOR gene.

Most importantly, a saturable dose-response relationship appears when data are binned and averaged (Fig. $6 \mathrm{~B}$ ). Ca-channel inhibition increases with MOR mRNA concentrations up to $\sim 15$ pM but gets no greater at higher concentrations. More than half of the nociceptor population express at $<15 \mathrm{pm}$. Therefore, most nociceptors express MOR mRNA at levels that result in submaximal inhibition by opioids.

Small and large nociceptors differ quantitatively

Figure 5 showed that large nociceptors, on average, have lower MOR mRNA and respond weakly to opioids compared with small nociceptors. Is this because more large nociceptors simply fail to express MOR mRNA, or do they express it at quantitatively lower levels? We found that the likelihood that a nociceptor had detectable MOR mRNA did not depend on cell size ( $p=0.1084$; $\chi^{2}$ test; $<30 \mu \mathrm{m}, 27$ expressors per 46 tested cells; $30-40 \mu \mathrm{m}, 52$ expressors per 81 tested cells; $>40 \mu \mathrm{m}, 30$ expressors per 64 tested cells). This agrees with in situ hybridization results showing that equal fractions of small and large sensory neurons express MOR antigen (Wang and Wessendorf, 2001).

A difference between large and small nociceptors is seen when we consider the amount of MOR mRNA in cells that have it. The largest cells that have MOR mRNA clearly have a lower mean concentration than smaller cells (Fig. 7A, solid bars) and also a lower mRNA number (Fig. 5B, inset). Only $20 \%$ of the largest nociceptors that have MOR mRNA express it at concentrations of $>15 \mathrm{pm}$, the value that correlates with maximal opioid sensitivity; in contrast, $60 \%$ of the smallest nociceptors express at $>15 \mathrm{pM}$ (Fig. 7A, hatched columns). We interpret Figures 6 and 7 to indicate that the opioid response of a nociceptor can be limited by its cellular concentration of MOR mRNA, and that this mechanism diminishes the opioid sensitivity of large, myelinated nociceptors.

\section{Discussion}

Our experiments demonstrate that: (1) non-nociceptive mechanosensors primarily fail to express MOR mRNA and are therefore opioid-insensitive; (2) if its MOR mRNA is $<15 \mathrm{pM}$, a nociceptor generally has submaximal opioid sensitivity; (3) a majority of nociceptors express MOR mRNA at $<15$ pM and therefore respond submaximally to opioids; (4) almost all large nociceptors, those likely to be myelinated and to mediate antinociceptive reflexes and the initial sensation of pain, express MOR mRNA at $<15 \mathrm{pm}$ and therefore have lower opioid sensitivity; and (5) small nociceptors, those likely to be unmyelinated and to mediate persisting pain, are much more likely to express MOR mRNA at levels that yield maximal opioid sensitivity.

We suggest (Fig. $7 B, C$ ) that this quantitative difference in the expression of MOR mRNA between myelinated and unmyelinated nociceptors contributes to the ability of opioids to suppress second pain while sparing first pain and antinociceptive reflexes (Price et al., 1985; Cooper et al., 1986; Yeomans et al., 1996). What other factors might contribute to the ability of opioids to distinguish different kinds of pain? At a cellular level, there might be differences in the expression of the several other relevant genes, those for G-proteins and those for Ca channels. Given the array of different genes involved, we were surprised that a single one, the MOR gene, could so clearly limit cellular response. An- 
A

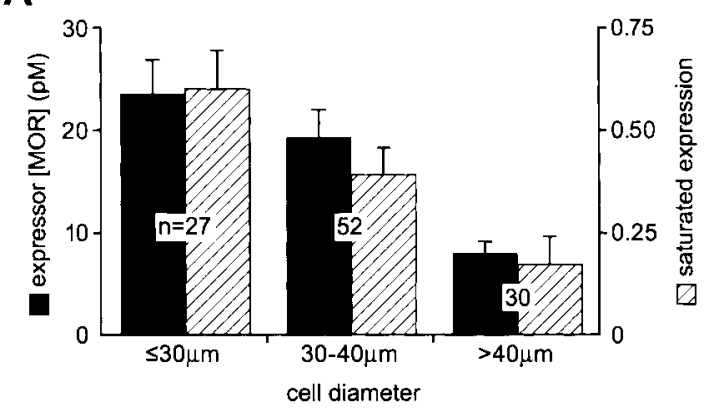

B
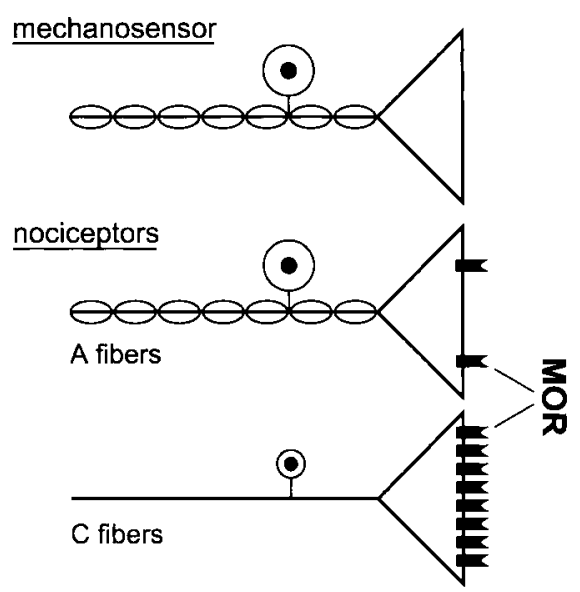

C

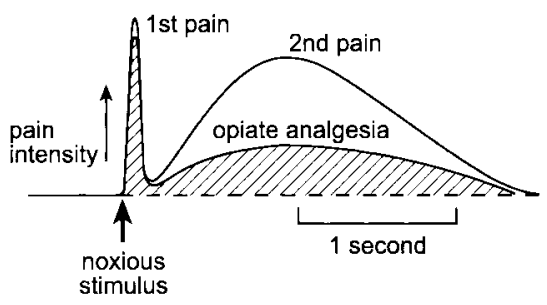

Figure 7. Opioid sensitivity of most large nociceptors is RNA limited. A, The mean concentration \pm SEM of MOR mRNA for different-sized tooth-pulp afferents in which it was detectable (black columns, left axis) and the fraction ( $\pm 68 \%$ confidence interval) of tooth-pulp afferents with detectable MOR mRNA that expressed it at $>15$ pм (hatched columns, right axis) decrease with increasing cell body size. Only a small fraction of large nociceptors express MOR mRNA at levels that lead to maximal opioid response. $B$, Hypothesis for selective opioid suppression of second pain. If protein densities at presynaptic terminals correspond to mRNA concentrations at the cell body, MOR is absent from virtually all non-nociceptive mechanosensor terminals and is present at low levels at terminals of most myelinated nociceptors. C, In this way, second pain, which is mediated by the unmyelinated terminals rich in MOR, can be selectively suppressed by opioids.

other factor could be protein turnover and trafficking, which would determine what delay occurs between a change in MOR mRNA level and the opioid response. Our experiments were performed at the cell body and, presumably, at a steady-state mRNA level. There might be very significant delays between nerve terminals and mRNA expression at the cell body.

At a systems level, opioids suppress the unpleasantness of pain while allowing its perception. This cannot be explained solely by spinal and peripheral actions of opioids. During noxious stimulation, endogenous opioids bind to receptors in the human thalamus and in select cortical regions, likely sites for distinguishing the affective and sensory actions of opioids (Zubieta et al., 2001).
Unlike perception, antinociceptive withdrawal reflexes are spinal, but here, too, there can be players other than the presynaptic opioid receptors. Opioids act on both the presynaptic Ca channels that we have studied and on postsynaptic K channels of nociceptive synapses (Grudt and Williams, 1994; Kohno et al., 1999). Postsynaptic projection neurons receive input from both myelinated and unmyelinated fibers, yet opioids inhibit only the signals arising from unmyelinated input (Jurna and Heinz, 1979; Woolf and Wall, 1986; Light and Willcockson, 1999). The most obvious mechanism would be presynaptic inhibition. However, if unmyelinated input is more likely to use interneurons, postsynaptic actions on interneurons would be selective for second pain.

\section{Fine control of gene expression and quantitative PCR}

MOR mRNA expression appears to be controlled in two different ways. One functions like a simple on-off switch: turned on only in nociceptors, it causes opioids to inhibit pain while sparing other sensations. The other functions like a dimmer switch that can set the MOR mRNA concentration to different levels in nociceptors that differ in myelination.

Fine control of gene expression might be caused by selective RNA stabilization (Wymore et al., 1996) or by control of transcription. A mechanism for precise transcriptional control has been deduced for the Endo 16 gene in sea urchins (Yuh et al., 1998), which provide great experimental advantages over neural tissue. The Endo 16 regulatory system consists of dozens of DNA binding proteins acting at a handful of upstream promoting or repressing DNA sequences. Most of this machinery is devoted to fine control of the transcription rate, and only a small fraction is devoted to determining the site at which transcription occurs in the animal (Yuh and Davidson, 1996). The methods generally used in neurobiology to detect gene transcription in individual cells, in situ hybridization and immunocytochemistry, can identify the anatomic location of gene expression but do not quantify it; thus, they would fail to detect action of the bulk of the control machinery for Endo 16.

Quantitative single-cell PCR proved sufficient to detect the presence of fine control of MOR mRNA level and, along with electrophysiological recordings, to suggest its physiological significance. Other quantitative single-cell PCR studies demonstrated that the levels of particular mRNAs determine glutamate receptor kinetics (Jonas et al., 1994), $\mathrm{K}^{+}$current amplitude (Baro et al., 1997), and $\mathrm{K}^{+}$current kinetics (Tkatch et al., 2000). It might be hoped that real-time PCR (Heid et al., 1996), which is easier to implement than the competitive PCR we used, might make such quantitative studies more common. However, a sideby-side comparison of different methods found that real-time PCR was inferior at detecting small numbers of cDNA molecules (Tkatch et al., 2000); this can be a disadvantage given the low copy number of some transcripts in single cells.

\section{Concentration versus copy number}

Some of our mRNA data are presented in the traditional way (copy number per cell) (Fig. 5B, inset) and some as cell-body concentration (Fig. 6). In most preparations, cells are all approximately the same size, so concentration and copy number are proportional. But cell volume varied 15 -fold in our population, so the difference needed to be confronted; moreover, the strong dependence on cell size for mRNA copy number of a housekeeping gene (Fig. $5 B$, inset) clearly demonstrates the need for normalization. Because mRNA freely diffuses from its site of manufacture to its site of reaction, we presume that concentration, not copy number, determines the probability of mRNA reaction and 
thereby provides the better predictor of the number of protein molecules generated.

\section{Relationship to other studies}

MOR is the sole receptor responsible for morphine analgesia: it is the only opioid receptor that binds morphine (Goldstein and Naidu, 1989; Raynor et al., 1994); its genetic knock-out eliminates the action of morphine in mice (Matthes et al., 1996; Sora et al., 1997). Our results extend this previous work by showing that fine control of MOR mRNA gives distinct $\mu$-opioid sensitivity to nociceptors that mediate different kinds of pain. The quantitative differences in MOR mRNA expression can explain why, in in situ hybridization, MOR mRNA is seen in the same fraction of large and small cells (Wang and Wessendorf, 2001), yet differences exist in opioid sensitivity between large and small cells (Taddese et al., 1995; Borgland et al., 2001). In agreement with hybridization, our quantitative RT-PCR found that large and small nociceptors are equally likely to express MOR mRNA above the detection threshold; however, when they express it, most small nociceptors express MOR mRNA at quantitatively higher levels than do most large nociceptors.

Our experiments do not address several important aspects of opioid action on sensory neurons. We have not studied here the other opioid receptors, $\delta$ and $\kappa$, both of which are detected in sensory ganglia (Ji et al., 1995; Zhu et al., 1998). These receptors do not bind exogenous opiates, but they do bind endogenous opioid peptides, and thereby function in the endogenous paincontrol system. There may also be multiple splice variants of MOR (Pasternak, 2001); our PCR primers were not targeted to distinguish these. We also do not address long-term changes in opioid sensitivity, such as occurs in either tolerance (Williams et al., 2001) or neurogenic pain (Iadarola and Caudle, 1997).

\section{Significance}

Our experiments suggest that fine control of MOR mRNA concentration in individual nociceptors controls their individual opioid sensitivity, and that this may contribute to the ability of opioids to suppress pain from a previous injury without blocking pain from a new injury or inhibiting reflex withdrawal from noxious stimuli. We found that many nociceptors (including small ones) fail to express MOR mRNA at levels that cause maximal opioid sensitivity; this suggests that upregulating MOR gene transcription in nociceptors might be a means of increasing the efficacy of opiate analgesia.

\section{References}

Abdulla FA, Smith PA (1998) Axotomy reduces the effect of analgesic opioids yet increases the effect of nociceptin on dorsal root ganglion neurons. J Neurosci 18:9685-9694.

Ahlquist ML, Edwall LG, Franzen OG, Haegerstam GA (1984) Perception of pulpal pain as a function of intradental nerve activity. Pain 19:353-366.

Arvidsson U, Riedl M, Chakrabarti S, Lee JH, Nakano AH, Dado RJ, Loh HH, Law PY, Wessendorf MW, Elde R (1995) Distribution and targeting of a $\mu$-opioid receptor (MOR1) in brain and spinal cord. J Neurosci 15:3328-3341.

Barnes WM (1992) The fidelity of Taq polymerase catalyzing PCR is improved by an N-terminal deletion. Gene 112:29-35.

Baro DJ, Levini RM, Kim MT, Willms AR, Lanning CC, Rodriguez HE, HarrisWarrick RM (1997) Quantitative single-cell-reverse transcription-PCR demonstrates that A-current magnitude varies as a linear function of shal gene expression in identified stomatogastric neurons. J Neurosci 17:6597-6610.

Borgland SL, Connor M, Christie MJ (2001) Nociceptin inhibits calcium channel currents in a subpopulation of small nociceptive trigeminal ganglion neurons in mouse. J Physiol (Lond) 536:35-47.
Campbell JN, LaMotte RH (1983) Latency to detection of first pain. Brain Res 266:203-208.

Chehadeh HE, Zerlauth G, Mannhalter JW (1995) Video image analysis of quantitative competitive PCR products: comparison of different evaluation methods. Biotechniques 26:28.

Cody FW, Lee RW, Taylor A (1972) A functional analysis of the components of the mesencephalic nucleus of the fifth nerve in the cat. J Physiol (Lond) 226:249-261.

Cooper BY, Vierck Jr CJ, Yeomans DC (1986) Selective reduction of second pain sensations by systemic morphine in humans. Pain 24:93-116.

Eckert SP, Taddese A, McCleskey EW (1997) Isolation and culture of rat sensory neurons having distinct sensory modalities. J Neurosci Methods 77:183-190.

Fields HL (1987) Pain. New York: McGraw-Hill.

Gilliland G, Perrin S, Blanchard K, Bunn HF (1990) Analysis of cytokine mRNA and DNA: detection and quantitation by competitive polymerase chain reaction. Proc Natl Acad Sci USA 87:2725-2729.

Goldstein A, Naidu A (1989) Multiple opioid receptors: ligand selectivity profiles and binding site signatures. Mol Pharmacol 36:265-272.

Grudt TJ, Williams JT (1994) $\mu$-Opioid agonists inhibit spinal trigeminal substantia gelatinosa neurons in guinea pig and rat. J Neurosci 14:1646-1654.

Harper AA, Lawson SN (1985) Conduction velocity is related to morphological cell type in rat dorsal root ganglion neurones. J Physiol (Lond) 359:31-46.

Heid CA, Stevens J, Livak KJ, Williams PM (1996) Real time quantitative PCR. Genome Res 6:986-994.

Iadarola JM, Caudle RM (1997) Good pain, bad pain. Science 278:239-240.

Ji RR, Zhang Q, Law PY, Low HH, Elde R, Hokfelt T (1995) Expression of $\mu$-, $\delta$-, and $\kappa$-opioid receptor-like immunoreactivities in rat dorsal root ganglia after carrageenan-induced inflammation. J Neurosci 15:8156-8166.

Jonas P, Racca C, Sakmann B, Seeburg PH, Monyer H (1994) Differences in $\mathrm{Ca}^{2+}$ permeability of AMPA-type glutamate receptor channels in neocortical neurons caused by differential GluR-B subunit expression. Neuron $12: 1281-1289$.

Jurna I, Heinz G (1979) Differential effects of morphine and opioid analgesics on A and C fibre-evoked activity in ascending axons of the rat spinal cord. Brain Res 171:573-576.

Jyvasjarvi E, Kniffki KD (1987) Cold stimulation of teeth: a comparison between the responses of cat intradental $\mathrm{A} \delta$ and $\mathrm{C}$ fibres and human sensation. J Physiol (Lond) 391:193-207.

Kieffer B (2000) Opioid receptors: from genes to mice. J Pain 1:45-50.

Kirschstein T, Greffrath W, Busselberg D, Treede RD (1999) Inhibition of rapid heat responses in nociceptive primary sensory neurons of rats by vanilloid receptor antagonists. J Neurophysiol 82:2853-2860.

Kohno T, Kumamoto E, Higashi H, Shimoji K, Yoshimura M (1999) Actions of opioids on excitatory and inhibitory transmission in substantia gelatinosa of adult rat spinal cord. J Physiol (Lond) 518:803-813.

Kyrozis A, Reichling DB (1995) Perforated-patch recording with gramicidin avoids artifactual changes in intracellular chloride concentration. J Neurosci Methods 57:27-35.

Lee KH, Chung K, Chung JM, Coggeshall RE (1986) Correlation of cell body size, axon size, and signal conduction velocity for individually labelled dorsal root ganglion cells in the cat. J Comp Neurol 243:335-346.

Lewis T, Pochin E (1937) The double pain response of the human skin to a single stimulus. Clin Sci 3:67-76.

Li X, Keith Jr DE, Evans CJ (1996) Multiple opioid receptor-like genes are identified in diverse vertebrate phyla. FEBS Lett 397:25-29.

Light AR, Willcockson HH (1999) Spinal laminae I-II neurons in rat recorded in vivo in whole cell, tight seal configuration: properties and opioid responses. J Neurophysiol 82:3316-3326.

Matthes HW, Maldonado R, Simonin F, Valverde O, Slowe S, Kitchen I, Befort K, Dierich A, Le Meur M, Dolle P, Tzavara E, Hanoune J, Roques BP, Kieffer BL (1996) Loss of morphine-induced analgesia, reward effect and withdrawal symptoms in mice lacking the $\mu$-opioid-receptor gene. Nature 383:819-823.

Moises HC, Rusin KI, Macdonald RL (1994) $\mu$-Opioid receptor-mediated reduction of neuronal calcium current occurs via a G(o)-type GTPbinding protein. J Neurosci 14:3842-3851.

Nagy I, Rang H (1999) Noxious heat activates all capsaicin-sensitive and also a sub-population of capsaicin-insensitive dorsal root ganglion neurons. Neuroscience 88:995-997. 
Narhi M, Yamamoto H, Ngassapa D, Hirvonen T (1994) The neurophysiological basis and the role of inflammatory reactions in dentine hypersensitivity. Arch Oral Biol 39:23S-30S.

Pasternak GW (2001) Insights into $\mu$ opioid pharmacology: the role of $\mu$ opioid receptor subtypes. Life Sci 68:2213-2219.

Price DD, Von der Gruen A, Miller J, Rafii A, Price C (1985) A psychophysical analysis of morphine analgesia. Pain 22:261-269.

Raynor K, Kong H, Chen Y, Yasuda K, Yu L, Bell GI, Reisine T (1994) Pharmacological characterization of the cloned $\kappa^{-}, \delta$-, and $\mu$-opioid receptors. Mol Pharmacol 45:330-334.

Rusin KI, Moises HC (1995) $\mu$-Opioid receptor activation reduces multiple components of high-threshold calcium current in rat sensory neurons. J Neurosci 15:4315-4327.

Seward E, Hammond C, Henderson G (1991) $\mu$-Opioid-receptor-mediated inhibition of the N-type calcium-channel current. Proc R Soc Lond B Biol Sci 244:129-135.

Sora I, Takahashi N, Funada M, Ujike H, Revay RS, Donovan DM, Miner LL, Uhl GR (1997) Opiate receptor knockout mice define $\mu$ receptor roles in endogenous nociceptive responses and morphine-induced analgesia. Proc Natl Acad Sci USA 94:1544-1549.

Sucher NJ, Deitcher DL (1995) PCR and patch-clamp analysis of single neurons. Neuron 14:1095-1100.

Taddese A, Nah SY, McCleskey EW (1995) Selective opioid inhibition of small nociceptive neurons. Science 270:1366-1369.

Tkatch T, Baranauskas G, Surmeier DJ (2000) Kv4.2 mRNA abundance and A-type $\mathrm{K}^{+}$current amplitude are linearly related in basal ganglia and basal forebrain neurons. J Neurosci 20:579-588.

Torebjork HE, Hallin RG (1973) Perceptual changes accompanying controlled preferential blocking of $\mathrm{A}$ and $\mathrm{C}$ fibre responses in intact human skin nerves. Exp Brain Res 16:321-332.
Triggle DJ (1999) The pharmacology of ion channels: with particular reference to voltage-gated $\mathrm{Ca}^{2+}$ channels. Eur J Pharmacol 375:311-325.

Wang H, Wessendorf MW (2001) Equal proportions of small and large DRG neurons express opioid receptor mRNAs. J Comp Neurol 429:590-600.

Wilding TJ, Womack MD, McCleskey EW (1995) Fast, local signal transduction between the $\mu$-opioid receptor and $\mathrm{Ca}^{2+}$ channels. J Neurosci 15:4124-4132.

Williams JT, Christie MJ, Manzoni O (2001) Cellular and synaptic adaptations mediating opioid dependence. Physiol Rev 81:299-343.

Woolf CJ, Wall PD (1986) Morphine-sensitive and morphine-insensitive actions of C-fibre input on the rat spinal cord. Neurosci Lett 64:221-225.

Wymore RS, Negulescu D, Kinoshita K, Kalman K, Aiyar J, Gutman GA, Chandy KG (1996) Characterization of the transcription unit of mouse Kv1.4, a voltage-gated potassium channel gene. J Biol Chem 271:15629-15634.

Yeomans DC, Pirec V, Proudfit HK (1996) Nociceptive responses to high and low rates of noxious cutaneous heating are mediated by different nociceptors in the rat: behavioral evidence. Pain 68:133-140.

Yuh CH, Davidson EH (1996) Modular cis-regulatory organization of Endo16, a gut-specific gene of the sea urchin embryo. Development 122:1069-1082.

Yuh CH, Bolouri H, Davidson EH (1998) Genomic cis-regulatory logic: experimental and computational analysis of a sea urchin gene. Science 279:1896-1902.

Zhu Y, Hsu MS, Pintar JE (1998) Developmental expression of the $\mu, \kappa$, and $\delta$ opioid receptor mRNAs in mouse. J Neurosci 18:2538-2549.

Zubieta JK, Smith YR, Bueller JA, Xu Y, Kilbourn MR, Jewett DM, Meyer CR, Koeppe RA, Stohler CS (2001) Regional $\mu$ opioid receptor regulation of sensory and affective dimensions of pain. Science 293:311-315. 